\title{
Insulin Resistance Is an Intrinsic Defect Independent of Fat Mass in Women with Turner's Syndrome
}

\author{
Burak Salgin $^{\text {a }}$ Rakesh Amin $^{\text {a }}$ Kevin Yuen ${ }^{a}$ Rachel M. Williams ${ }^{a}$ \\ Peter Murgatroyd $^{\text {b }}$ David B. Dunger ${ }^{\text {a }}$ \\ ${ }^{a}$ University Department of Paediatrics, and ${ }^{b}$ Wellcome Trust Clinical Research Facility, University of Cambridge, \\ Cambridge, UK
}

\section{Key Words}

Turner's syndrome $\cdot$ Insulin resistance $\cdot$ Body composition

\begin{abstract}
Background/Aims: Turner's syndrome (TS) is associated with increased insulin resistance and adiposity, which might be associated with type 2 diabetes in later life. We aimed to determine whether the defect in insulin sensitivity is a primary intrinsic defect in TS or dependent on variation in body composition. Methods: Sixteen women with TS not on growth hormone replacement but receiving oestrogen replacement therapy [age (mean \pm $\mathrm{SD}): 30.2 \pm 8.5$ years; height-corrected fat-free mass: $26.1 \pm 3.1 \mathrm{~kg} /$ height] and a control group of 16 normal healthy women (age: $30.1 \pm 8.2$ years; height-corrected fat-free mass: $25.9 \pm 2.4 \mathrm{~kg} /$ height) were studied. Fasting blood samples were obtained for measurement of glucose, insulin, IGF-I, IGFBP-1, IGFBP-3 and lipid levels. The hyperinsulinaemic euglycaemic clamp was performed to assess peripheral insulin sensitivity ( $M$ value), and the Homeostasis Model Assessment (HOMA-S) was used to estimate fasting insulin sensitivity. Body composition
\end{abstract}

was assessed using a dual-energy X-ray absorptiometry scan. Results: Fasting insulin sensitivity (HOMA-S 103.2 \pm 78.6 vs. $193.9 \pm 93.5, p=0.006$ ) was lower in TS subjects compared to controls as was whole-body insulin sensitivity (M value $2.9 \pm 1.9$ vs. $5.5 \pm 2.6 \mathrm{mg} / \mathrm{kg} / \mathrm{min}$, $\mathrm{p}=0.003$ ). In a multiple regression analysis the Turner karyotype was significantly related to insulin sensitivity ( $p=0.008$ ) independent of any differences in fat-free mass and percent whole-body fat mass. Conclusion: The increased insulin resistance in women with TS is independent of measures of body composition and may represent an intrinsic defect related to their chromosomal abnormality.

Copyright () 2006 S. Karger AG, Basel

\section{Introduction}

Women with Turner's syndrome (TS) have a fourfold increased relative risk of developing type 2 diabetes (T2DM) and a threefold increase in overall mortality, with diabetes mellitus contributing to $25 \%$ of the causes of death in adulthood $[1,2]$. Impaired glucose tolerance is reported with an increased frequency in adolescents

\section{KARGER \\ Fax +4161306 1234 E-Mailkarger@karger.ch} www.karger.com
(C) 2006 S. Karger AG, Basel 0301-0163/06/0652-0069\$23.50/0 www.karger.com/hre
Prof. David B. Dunger

University Department of Paediatrics, University of Cambridge

Addenbrooke's Hospital, Level 8, Box 116

Cambridge CB2 2QQ (UK)

Tel. +44 1223336 886, Fax +44 1223336 996, E-Mail dbd25@cam.ac.uk 
[3-5] and adults with TS [6, 7], with one study suggesting that insulin resistance may be the primary defect in the Turner metabolic phenotype [8].

Despite the increased incidence of glucose intolerance, the exact mechanism in these patients remains unclear, although an impaired insulin secretion in response to exogenous glucagon and tolbutamide [9] as well as a defect of insulin action, as assessed by the hyperinsulinaemic euglycaemic clamp, have been previously implicated [5, 8]. The development of T2DM in TS has been suggested to be due to deficient insulin responses to oral and intravenous glucose loads [10]; however, insulin levels in nondiabetic and diabetic women with TS have been reported to be high, normal, or low $[5,11,12]$. Women with TS tend to demonstrate increased adiposity compared with age-matched controls [6, 13], and their hypogonadism and hormone replacement therapy may pose additional confounding effects in studies of glucose metabolism. In many studies there have been problems in obtaining wellmatched groups controlling for age, body mass and composition $[6,9,10,14]$. In particular, body mass index (BMI) fails to reflect differences in adiposity as the phenotype of TS is characterised by short stature. The height and percent fat-free mass deficit in women with TS has to be taken into consideration in order to increase the validity of the calculated difference in insulin resistance.

The present study was therefore undertaken to measure fasting insulin sensitivity using the Homeostasis Model Assessment (HOMA) and peripheral insulin sensitivity using the gold standard hyperinsulinaemic euglycaemic clamp technique in women with TS compared to age-matched normal healthy female controls, correcting data for differences in body composition and height. By controlling for these potentially confounding variables, we hoped to clarify whether the insulin resistance is an intrinsic defect per se or dependent on variation in body size.

\section{Subjects and Methods}

\section{Subjects}

Women with TS were recruited from the adult Turner clinics at Addenbrooke's Hospital, Cambridge and Northampton General Hospital. The diagnosis of TS was verified by peripheral leukocyte karyotype studies. Subjects with pre-existing renal disease, liver disease, cardiovascular disease and diabetes mellitus were excluded from the study. Out of the 16 adult women with TS, 10 had an XO and 4 a mosaic karyotype, while 2 had a ring chromosome pattern. Sixteen healthy women acted as controls. They were all volunteers recruited from staff at Addenbrooke's Hospital. The demographic details are listed in table 1. All women with TS were not receiving growth hormone therapy, but 15/16 were on oestrogen/progesterone replacement (one subject with a mosaic genotype had normal spontaneous menses). Study subjects were otherwise in good general health and were euthyroid as determined by screening laboratory tests. The study protocol was approved by the Cambridge, Aylesbury and Northampton Local Research Ethics Committees, and all subjects provided written informed consent prior to study entry.

\section{Study Design}

Following a 12-hour overnight fast, patients with TS and control subjects were admitted to the Addenbrooke's Wellcome Trust Clinical Research Facility Investigation Ward. Height and weight measurements were obtained using a wall-mounted stadiometer and electronic scales, and BMI was calculated as weight $/$ height ${ }^{2}\left(\mathrm{~kg} / \mathrm{m}^{2}\right)$. Body composition was then assessed using a dual-energy X-ray absorptiometry scanner with a Prodigy Oracle Lunar Corp (Madison, Wisc., USA) coupled to Lunar Corps software. Absolute (kg) and relative (\%) whole-body, truncal and abdominal (defined as: from the dome of the diaphragm to the top of the greater trochanter) fat content as well as fat-free mass were assessed [15]. Fasting blood samples were collected for the determination of glucose, insulin, IGF-I, IGFBP-1, IGFBP-3 and lipid concentrations. A one-step hyperinsulinaemic, euglycaemic clamp was then performed between $08.00-10.00 \mathrm{~h}$. At the start of each clamp, the basilic vein in the antecubital fossa of one arm was cannulated and an insulin bolus (Actrapid; Novo Nordisk, Bagsvaerd, Denmark) of $2.3 \mathrm{mU} / \mathrm{kg}$ was administered followed by an insulin infusion of $0.5 \mathrm{mU} / \mathrm{kg} / \mathrm{min}$ for $2 \mathrm{~h}$. For blood sampling, the basilic vein of the other arm was cannulated and the arm was put into a heated sleeve $\left(28^{\circ} \mathrm{C}\right)$ in order to arterialise blood samples. Blood glucose concentrations were measured 5-minutely and maintained at a concentration of $4 \mathrm{mmol} / \mathrm{l}$ using a variable rate infusion of intravenous $20 \%$ dextrose. Throughout the clamp, 30-minutely blood samples were also collected for insulin analysis.

\section{Assays}

Blood glucose concentrations were measured using $25-\mu 1$ whole blood samples on a Y.S.I. model 2300 stat plus analyser (Yellow Spring Instruments, Farnborough, UK). The intra-assay coefficient of variation $(\mathrm{CV})$ at $4.1 \mathrm{mmol} / \mathrm{l}$ was $1.5 \%$. The equivalent interassay $\mathrm{CVs}$ at this glucose concentration were 2.8 and $1.7 \%$ at $14.1 \mathrm{mmol} / \mathrm{l}$. Plasma insulin, IGF-I, IGFBP-1, IGFBP-3 concentrations were measured using DSL enzyme-linked immunosorbent assays (Oxford Bio-Innovations, Upper Heyford, UK) according to the manufacturer's instructions. The sensitivity of the insulin assay was $1.56 \mathrm{pmol} / 1$. Intra-assay $\mathrm{CVs}$ were $4.4 \%$ at $62 \mathrm{pmol} / 1$ and $5.1 \%$ at $215 \mathrm{pmol} / \mathrm{l}$, and equivalent inter-assay $\mathrm{CVs}$ were 4.3 and $2.9 \%$, respectively. For plasma IGF-I concentrations, the sensitivity of the assay was $0.03 \mathrm{ng} / \mathrm{ml}$. Intra-assay CVs were 8.8 and $9.4 \%$ at 107 and $262 \mathrm{ng} / \mathrm{ml}$, respectively, and equivalent inter-assay CVs were 6.1 and $8.0 \%$. For IGFBP-1, the sensitivity of this assay was $0.25 \mathrm{ng} / \mathrm{ml}$. Intra-assay CVs were $6.1 \%$ at $7.0 \mathrm{ng} / \mathrm{ml}$ and $5.3 \%$ at $48.4 \mathrm{ng} / \mathrm{ml}$, and equivalent inter-assay CVs were 10.4 and $5.1 \%$, respectively. For IGFBP-3, the sensitivity of this assay was 0.04 $\mathrm{ng} / \mathrm{ml}$. Intra-assay imprecision CVs were 4.9 and $2.8 \%$ at 5.2 and $34.7 \mathrm{ng} / \mathrm{ml}$, respectively, and equivalent inter-assay imprecision CVs were 9.7 and $1.9 \%$. Serum cholesterol, triglyceride and HDL cholesterol samples were assayed in singleton on the Dimension 
Table 1. Cohort characteristics

\begin{tabular}{lccc}
\hline & Controls & Turners & Significance \\
\hline Age, years & $29.5(20.7-43.2)$ & $29.9(16.5-46.4)$ & NS \\
Height, cm & $165.8(6.5)$ & $149.9(6.8)$ & $<0.001$ \\
Weight, kg & $60.9(45.4-100.6)$ & $62.2(44.9-98.8)$ & NS \\
BMI & $22.8(3.7)$ & $27.9(5.4)$ & 0.004 \\
\hline Body composition (not corrected for height) & & & 0.004 \\
Whole-body fat mass/fat-free mass ratio & $0.49(0.04)$ & $0.70(0.05)$ & NS \\
Whole-body fat mass, kg & $20.1(9.0)$ & $26.5(10.2)$ & 0.004 \\
Whole-body fat mass, \% & $30.6(7.6)$ & $39.3(5.9)$ & NS \\
Truncal fat mass, kg & $9.3(5.0)$ & $13.1(6.4)$ & 0.01 \\
Truncal fat mass, \% & $29.6(9.1)$ & $38.4(6.7)$ & $\mathrm{NS}$ \\
Abdominal fat mass, kg & $6.7(4.4)$ & $9.3(4.6)$ & 0.02 \\
Abdominal fat mass, \% & $31.8(10.4)$ & $41.2(7.7)$ & 0.004 \\
Fat-free mass, kg & $43.1(5.5)$ & $39.3(5.1)$ & $\mathrm{NS}$ \\
Fat-free mass, \% & $69.4(7.6)$ & $60.7(5.9)$ & 0.02 \\
\hline Body composition (corrected for height) & & & 0.03 \\
Whole-body fat mass, kg/height & $12.0(1.3)$ & $17.6(2.0)$ & $\mathrm{NS}$ \\
Truncal fat mass, kg/height & $5.6(0.7)$ & $8.7(1.3)$ & $\mathrm{NS}$ \\
Abdominal fat mass, kg/height & $4.0(0.6)$ & $6.2(0.9)$ & $26.1(3.1)$ \\
Fat-free mass, kg/height & $25.9(2.4)$ & &
\end{tabular}

Data are expressed as mean (SD) or median (range). NS = No significance.

RXL system (Dade Behring) using reagents and calibrants supplied by the manufacturer, whereas LDL cholesterol was calculated using Friedewald's formula [16].

\section{Calculations}

As fasting glucose levels are largely determined by basal hepatic glucose production [17, 18], HOMA [19, 20], calculated using the HOMA-CIGMA Calculator Program, was employed as a proxy for hepatic insulin sensitivity. A high HOMA score denotes increased hepatic insulin sensitivity. HOMA has previously been validated against independent measures of insulin sensitivity, including clamp-derived measures [21-23]. Peripheral insulin sensitivity was determined during the final $30 \mathrm{~min}$ of the hyperinsulinaemic euglycaemic clamp from the mean rate of intravenous infusion of 20\% dextrose required to maintain euglycaemia at $4 \mathrm{mmol} / \mathrm{l}(\mathrm{M}$ value, $\mathrm{mg} / \mathrm{kg} / \mathrm{min}$ ). The IGF-I/IGFBP-3 molar ratios were calculated by taking into account the molecular weights of IGF-I (7.6 kDa) and IGFBP-3 (50 kDa).

\section{Statistics}

All analyses were performed using SPSS version 10 (SPSS, Chicago, Ill., USA). One-way analysis of variance (ANOVA) was used to compare differences between groups. Weight, IGF-I and IGFI/IGFBP-3 were logarithmically transformed to allow parametric testing, whereas for non-parametric testing of baseline plasma insulin levels, the Mann-Whitney U test was applied. A multiple regression model was used to investigate the effects of the Turner karyotype, fat-free mass (corrected for differences in height be- tween cohorts) and percent whole-body fat mass on the glucose infusion rate during the clamp. $\mathrm{p}<0.05$ was considered statistically significant.

\section{Results}

\section{Demographics}

There were no differences in age and weight between the women with TS and the normal healthy controls. However, subjects with TS were shorter, resulting in greater BMIs (table 1).

\section{Body Composition Data}

TS women demonstrated higher relative (\%) wholebody, truncal and abdominal fat mass ( $\mathrm{p}=0.004, \mathrm{p}=$ $0.01, \mathrm{p}=0.02$, respectively; table 1 ). When corrected for differences in height, TS subjects had greater whole-body $(\mathrm{p}=0.02)$ and truncal fat mass $(\mathrm{p}=0.03$; table 1$)$. Relative $(\%)$ but not absolute $(\mathrm{kg})$ fat-free mass was increased in controls $(\mathrm{p}=0.004)$, but TS women had more fat per $\mathrm{kg}$ fat-free mass $(\mathrm{p}=0.004$; table 1$)$. 
Table 2. Baseline data

\begin{tabular}{lccl}
\hline Fasting data & Controls & Turners & Significance \\
\hline Glucose, mmol/1 & $4.5(0.3)$ & $4.6(0.8)$ & $\mathrm{NS}$ \\
IGF-I, ng/ml & $218.3(148.1-488.0)$ & $210.1(45.9)$ & $\mathrm{NS}$ \\
IGFBP-1, ng/ml & $26.2(12.6)$ & $25.6(13.8)$ & $\mathrm{NS}$ \\
IGFBP-3, $\mu \mathrm{g} / \mathrm{ml}$ & $4.1(0.7)$ & $4.3(0.9)$ & $\mathrm{NS}$ \\
IGF-I/IGFBP-3 molar ratio & $0.2(0.2-0.5)$ & $0.2(0.1-0.4)$ & $\mathrm{NS}$ \\
Plasma insulin level, pmol/1 & $33.2(18.0-80.5)$ & $119.6(18.4-578.7)$ & 0.007 \\
HOMA-S, \% & $193.9(93.5)$ & $103.2(78.6)$ & 0.006 \\
\hline Cardiovascular risk factors & & & \\
Cholesterol, mmol/1 & $4.1(0.5)$ & $4.1(1.2)$ & $\mathrm{NS}$ \\
Triglycerides, mmol/1 & $0.7(0.3)$ & $1.0(0.6)$ & 0.03 \\
HDL, mmol/1 & $1.7(0.4)$ & $1.3(0.4)$ & 0.01 \\
LDL, mmol/l & $2.2(0.5)$ & $2.4(0.9)$ & $\mathrm{NS}$ \\
Cholesterol/HDL & $2.5(0.7)$ & $3.2(1.0)$ & 0.025 \\
\hline
\end{tabular}

Data are expressed as mean (SD) or median (range). NS = No significance.

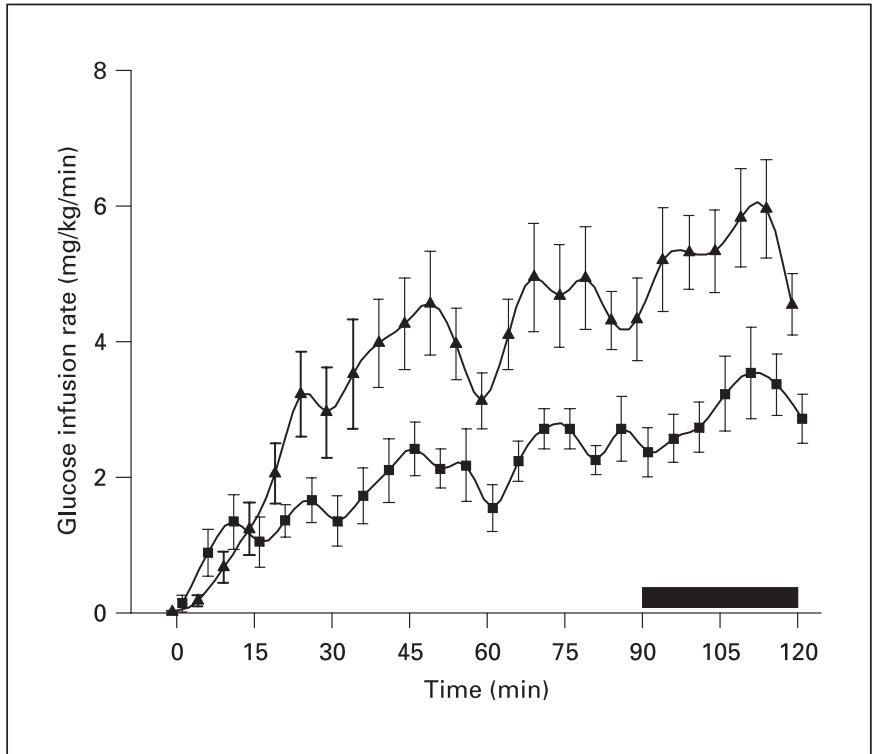

Fig. 1. Glucose requirement for healthy women $(\boldsymbol{\Delta})$ and subjects with TS ( $\square$ ) during the 2-hour one-step hyperinsulinaemic euglycaemic clamp. The steady state (final $30 \mathrm{~min}$ ) is indicated by the black bar. Symbols represent means \pm SEM.

\section{Fasting Data}

Compared to control females, glucose levels were similar, but subjects with TS had higher fasting insulin concentrations $(p=0.007)$ and decreased fasting insulin sensitivity (HOMA-S \%, p = 0.006). IGF-I and IGF binding protein levels did not differ significantly (table 2 ).
Table 3. Clamp parameters

\begin{tabular}{lccl}
\hline & Controls & Turners & Significance \\
\hline Glucose, mmol/1 & $4.2(0.3)$ & $4.4(0.7)$ & $\mathrm{NS}$ \\
$\begin{array}{l}\text { Insulin, mU/1 } \\
\begin{array}{c}\text { Glucose requirement } \\
\mathrm{mg} / \mathrm{kg} / \mathrm{min}\end{array}\end{array}$ & $30.8(9.3)$ & $37.2(29.5)$ & $\mathrm{NS}$ \\
& $5.5(2.6)$ & $2.9(1.9)$ & 0.003
\end{tabular}

Data are expressed as mean (SD). NS = No significance.

\section{Insulin Sensitivity Assessed by Clamp Studies}

Whole-body insulin sensitivity in subjects with TS was significantly lower compared with control females $(2.9 \pm$ 1.9 vs. $5.5 \pm 2.6 \mathrm{mg} / \mathrm{kg} / \mathrm{min}, \mathrm{p}=0.003$; fig. 1 and table $3)$. This difference persisted after adjustment for the whole-body fat mass/fat-free mass ratio, fat-free mass (including correction for variation in height between subjects) and/or relative (\%) whole-body fat mass (table 4). There were no significant correlations between insulin sensitivity and percent abdominal or percent truncal fat mass in the TS cohort, controls or the combined group.

\section{Cardiovascular Risk Factors}

No differences in cholesterol and LDL cholesterol levels were observed, but subjects with TS had higher triglyceride and cholesterol/HDL ratios $(\mathrm{p}=0.03$ and 0.025 , respectively) and lower HDL levels $(\mathrm{p}=0.01)$ compared to control females (table 2). 


\section{Effect of Oestrogen Replacement on Insulin}

\section{Sensitivity}

No significant differences were observed between those receiving natural $(\mathrm{n}=8)$ or synthetic oestrogen $(\mathrm{n}=7)$, and the subject that did not receive any supplementation $(n=1)$. However, a trend towards a reduction in insulin sensitivity with synthetic compared to natural and no supplementation was evident $(2.1 \pm 1.9$ vs. $3.5 \pm 2.3$ and $4.1 \mathrm{mg} / \mathrm{kg} / \mathrm{min} ; \mathrm{p}=0.3$, ANOVA).

\section{Discussion}

In this study, we used the hyperinsulinaemic euglycaemic clamp technique and HOMA to compare tissue sensitivity to insulin in non-diabetic women with TS and healthy female controls. Our data demonstrated that women with TS, who have normal fasting glucose concentrations, are more insulin resistant than agematched controls. As the phenotype of TS is characterised by a short stature, BMI does not accurately reflect differences in adiposity. The height and percent fat-free mass deficit in women with TS has to be taken into consideration in order to increase the validity of the calculated difference in insulin resistance. When corrected for differences in height, fat-free mass was similar in our TS and control subjects, yet women with TS were more insulin resistant. This relative low insulin sensitivity was also independent of the fact that TS subjects had more fat per $\mathrm{kg}$ fat-free mass as well as increased percent whole-body and percent abdominal fat mass when compared to controls.

A number of earlier studies also came to the conclusion that there is a relative increase in insulin resistance associated with TS. However, the height deficit of TS women was not taken into account and subject numbers were smaller in the two studies that made use of the hyperinsulinaemic euglycaemic clamp [5, 8]. Stoppoloni et al. [5] included controls that were considerably older than the subjects with TS, and Caprio et al. [8] based their results on a study population of relatively young women. In contrast to our study, AvRuskin et al. [9] did not comment on the insulin sensitivity of subjects with TS but provided evidence for an impaired insulin secretion in response to exogenous glucagon and tolbutamide in a relatively young cohort (age range: 6.5-17 years). There is an inherent difficulty in finding height-matched controls for women with TS. However, our study provides evidence for an increased insulin resistance in TS that is independent of percent fat and height-corrected lean body mass, both of
Table 4. Multiple regression analysis

\begin{tabular}{lrrl}
\hline & B & F & $\begin{array}{l}\text { Signif- } \\
\text { icance }\end{array}$ \\
\hline $\begin{array}{l}\text { Turner vs. controls } \\
\text { Whole-body fat mass/ } \\
\text { fat-free mass ratio }\end{array}$ & -2.68 & 2.63 & 0.008 \\
Fat-free mass, kg/height & -15.48 & & NS \\
Whole-body fat mass, \% & 0.18 & NS \\
& 0.41 & NS \\
\hline
\end{tabular}

Effect of the Turner karyotype, whole-body fat mass/fat-free mass ratio, fat-free (corrected for height) and relative whole body fat mass on glucose requirements during the clamp.

$\mathrm{R}^{2}=0.27$ (adjusted $\mathrm{R}^{2}=0.14$ ).

which have been shown to be significant determinants of insulin sensitivity $[1,6]$.

The effect of sex hormone replacement therapy on insulin sensitivity remains unclear [6, 24]. However, Gravholt et al. [1] showed that insulin sensitivity was similar before and during replacement in a TS cohort. In our study, all but one woman with TS (mosaic karyotype, who had spontaneous menses) were receiving oestrogen. No difference in the degree of insulin resistance was observed between those receiving synthetic or natural oestrogen, and the subject without any supplementation. Nevertheless, a trend towards a relative reduction in insulin sensitivity with synthetic compared to natural and no oestrogen replacement therapy was evident; the analysis was restricted by small sample sizes. Growth hormone poses a further potential confounding factor when investigating insulin sensitivity as replacement therapies have been shown to exacerbate insulin resistance in TS, but effects were reversed 6-12 months after treatment discontinuation $[25,26]$. Our subjects had stopped growth hormone therapy for more than 5 years before the study and hence this was unlikely to be confounding.

The role of IGF-I in regulating glucose homeostasis and insulin sensitivity has become increasingly recognised in recent years [27, 28]. Recombinant human IGF-I enhances insulin sensitivity in insulin resistant states such as T2DM $[29,30]$ and insulin resistance syndromes [31, 32]. The growth retardation that characterises TS suggests a peripheral end-organ resistance to IGF-I [33] as these women generally require higher doses of $\mathrm{GH}$ in order to accelerate growth. It has also been proposed that IGF-I bioactivity is maintained primarily through free IGF-I [34], and that free IGF-I levels are reduced in TS despite 
normal total IGF-I [35]. Thus, it could be hypothesised that decreased end-organ responsiveness and reduced levels of free IGF-I may contribute to the reduction in insulin sensitivity in women with TS.

Apart from insulin resistance, dyslipidaemia also confers an increased risk of cardiovascular disease [36, 37]. Hypercholesterolaemia has been reported in adolescents with TS which was found to be independent of BMI and unrelated to the karyotype [38, 39]. However, it has not been possible to confirm that cholesterol levels differ from those of karyotypically normal women $[6,25,40]$. We noted that women with TS had higher triglyceride levels, which may be a direct consequence of their obesity and hyperinsulinaemia [41].

Earlier studies have provided evidence that a putative intrinsic defect underlying the insulin resistance in TS may reside at the level of the muscle. Caprio et al. [8] used the indirect calorimetry technique to demonstrate decreased non-oxidative glucose disposal, which implies an early metabolic alteration in glucose metabolism. Gravholt et al. [14] found that women with TS have enlarged type IIa muscle fibres, suggesting a decreased oxygen and substrate supply for glucose metabolism. Insulin resistance has been reported from an early age in monosomic TS women compared to normal matched controls as well as in mosaic TS females, even before the commencement of growth hormone and sex steroid replacement [42]. We were not able to confirm that a monosomic karyotype confers a more insulin-resistant state than a mosaic karyotype as there were only 6 subjects in the non-monosomic group. Genome-wide scans for genes involved in T2DM have not been consistent in showing linkage to the $\mathrm{X}$ chromosome. However one peak on the $\mathrm{Xq}$ region was detected with a logarithm of the odds score of 2.99 in US Caucasians [43]. Also, the insulin receptor substrate 4 has been mapped to Xp22.3-23 and represents a putative candidate gene for an insulin-resistant phenotype; insulin receptor substrate 1 and 2 knockout mice are already in use as experimental models of insulin resistance [44], and there is some evidence for a role of these genes in humans [45]. A larger study is required to investigate the precise influence of the karyotype on insulin sensitivity.

In conclusion, our findings demonstrate an impaired peripheral and hepatic insulin sensitivity in TS. By excluding secondary causes, such as adverse body composition and sex steroid effects due to ovarian failure, our data implicate an intrinsic defect, which is related to the karyotype. A further study is warranted to identify the X-chromosome locus and gene(s) involved in this distinct metabolic phenotype.

\section{References}

-1 Gravholt CH, Juul S, Naeraa RW, Hansen J: Morbidity in Turner syndrome. J Clin Epidemiol 1998;51:147-158.

$\checkmark 2$ Price WH, Clayton JF, Collyer S, De Mey R, Wilson J: Mortality ratios, life expectancy, and causes of death in patients with Turner's syndrome. J Epidemiol Community Health 1986; 40:97-102.

-3 Polychronakos C, Letarte J, Collu R, Ducharme JR: Carbohydrate intolerance in children and adolescents with Turner syndrome. J Pediatr 1980;96:1009-1014.

4 Rasio E, Antaki A, Van Campenhout J: Diabetes mellitus in gonadal dysgenesis: studies of insulin and growth hormone secretion. Eur J Clin Invest 1976;6:59-66.

$\checkmark 5$ Stoppoloni G, Prisco F, Alfano C, Iafusco D, Marrazzo G, Paolisso G: Characteristics of insulin resistance in Turner syndrome. Diabetes Metab 1990;16:267-271.

-6 Gravholt CH, Naeraa RW, Nyholm B, Gerdes LU, Christiansen E, Schmitz O, Christiansen JS: Glucose metabolism, lipid metabolism, and cardiovascular risk factors in adult Turner's syndrome. The impact of sex hormone replacement. Diabetes Care 1998;21:10621070.
7 Holl RW, Kunze D, Etzrodt H, Teller W, Heinze E: Turner syndrome: final height, glucose tolerance, bone density and psychosocial status in 25 adult patients. Eur J Pediatr 1994; 153:11-16

-8 Caprio S, Boulware S, Diamond M, Sherwin RS, Carpenter TO, Rubin K, Amiel S, Press M, Tamborlane WV: Insulin resistance: an early metabolic defect of Turner's syndrome. J Clin Endocrinol Metab 1991;72:832-836.

-9 AvRuskin TW, Crigler JF Jr, Soeldner JS: Turner's syndrome and carbohydrate metabolism. I. Impaired insulin secretion after tolbutamide and glucagon stimulation tests: evidence of insulin deficiency. Am J Med Sci 1979;277:145152.

10 Bakalov VK, Cooley MM, Quon MJ, Luo ML, Yanovski JA, Nelson LM, Sullivan G, Bondy CA: Impaired insulin secretion in the Turner metabolic syndrome. J Clin Endocrinol Metab 2004;89:3516-3520.

11 Gravholt CH, Naeraa RW, Brixen K, Kastrup KW, Mosekilde L, Jorgensen JO, Christiansen JS: Short-term growth hormone treatment in girls with Turner syndrome decreases fat mass and insulin sensitivity: a randomized, doubleblind, placebo-controlled, crossover study. Pediatrics 2002;110:889-896.
12 Neufeld ND, Lippe B, Sperling MA: Carbohydrate intolerance in gonadal dysgenesis: a new model of insulin resistance. Diabetes 1980; 25(suppl):379.

13 Landin-Wilhelmsen K, Bryman I, Wilhelmsen $\mathrm{L}$ : Cardiac malformations and hypertension, but not metabolic risk factors, are common in Turner syndrome. J Clin Endocrinol Metab 2001;86:4166-4170.

14 Gravholt CH, Nyholm B, Saltin B, Schmitz O, Christiansen JS: Muscle fiber composition and capillary density in Turner syndrome: evidence of increased muscle fiber size related to insulin resistance. Diabetes Care 2001;24: 1668-1673.

15 Taylor RW, Keil D, Gold EJ, Williams SM, Goulding A: Body mass index, waist girth, and waist-to-hip ratio as indexes of total and regional adiposity in women: evaluation using receiver operating characteristic curves. Am J Clin Nutr 1998;67:44-49.

16 Friedewald WT, Levy RI, Fredrickson DS: Estimation of the concentration of low-density lipoprotein cholesterol in plasma, without use of the preparative ultracentrifuge. Clin Chem 1972; 18:499-502. 
-17 Campbell PJ, Mandarino LJ, Gerich JE: Quantification of the relative impairment in actions of insulin on hepatic glucose production and peripheral glucose uptake in non-insulin-dependent diabetes mellitus. Metabolism 1988; $37: 15-21$.

18 DeFronzo RA, Ferrannini E, Simonson DC: Fasting hyperglycemia in non-insulin-dependent diabetes mellitus: contributions of excessive hepatic glucose production and impaired tissue glucose uptake. Metabolism 1989;38: 387-395.

19 Levy JC, Matthews DR, Hermans MP: Correct homeostasis model assessment (HOMA) evaluation uses the computer program. Diabetes Care 1998;21:2191-2192.

-20 Matthews DR, Hosker JP, Rudenski AS, Naylor BA, Treacher DF, Turner RC: Homeostasis model assessment: insulin resistance and betacell function from fasting plasma glucose and insulin concentrations in man. Diabetologia 1985;28:412-419.

-21 Bonora E, Targher G, Alberiche M, Bonadonna RC, Saggiani F, Zenere MB, Monauni T, Muggeo M: Homeostasis model assessment closely mirrors the glucose clamp technique in the assessment of insulin sensitivity: studies in subjects with various degrees of glucose tolerance and insulin sensitivity. Diabetes Care 2000;23:57-63.

-22 Haffner SM, Miettinen H, Stern MP: The homeostasis model in the San Antonio Heart Study. Diabetes Care 1997;20:1087-1092.

-23 Hermans MP, Levy JC, Morris RJ, Turner RC: Comparison of insulin sensitivity tests across a range of glucose tolerance from normal to diabetes. Diabetologia 1999;42:678-687.

$\checkmark 24$ Elsheikh M, Bird R, Casadei B, Conway GS, Wass JA: The effect of hormone replacement therapy on cardiovascular hemodynamics in women with Turner's syndrome. J Clin Endocrinol Metab 2000;85:614-618.

25 Sylven L, Hagenfeldt K, Brondum-Nielsen K, von Schoultz B: Middle-aged women with Turner's syndrome. Medical status, hormonal treatment and social life. Acta Endocrinol (Copenh) 1991;125:359-365.

-26 van Teunenbroek A, de Muinck KeizerSchrama SM, Aanstoot HJ, Stijnen T, Hoogerbrugge N, Drop SL: Carbohydrate and lipid metabolism during various growth hormone dosing regimens in girls with Turner syndrome. Dutch Working Group on Growth Hormone. Metabolism 1999;48:7-14.
27 Sandhu MS, Heald AH, Gibson JM, Cruickshank JK, Dunger DB, Wareham NJ: Circulating concentrations of insulin-like growth factor-I and development of glucose intolerance: a prospective observational study. Lancet 2002;359:1740-1745.

28 Sesti G, Sciacqua A, Cardellini M, Marini MA, Maio R, Vatrano M, Succurro E, Lauro R, Federici M, Perticone F: Plasma concentration of IGF-I is independently associated with insulin sensitivity in subjects with different degrees of glucose tolerance. Diabetes Care 2005;28:120 125.

29 Cusi K, DeFronzo R: Recombinant human insulin-like growth factor I treatment for 1 week improves metabolic control in type 2 diabetes by ameliorating hepatic and muscle insulin resistance. J Clin Endocrinol Metab 2000;85: 3077-3084.

30 Moses AC, Morrow LA, O’Brien M, Moller DE, Flier JS: Insulin-like growth factor I (rhIGF-I) as a therapeutic agent for hyperinsulinemic insulin-resistant diabetes mellitus. Diabetes Res Clin Pract 1995;28(suppl):S185S194.

31 Morrow LA, O’Brien MB, Moller DE, Flier JS, Moses AC: Recombinant human insulin-like growth factor-I therapy improves glycemic control and insulin action in the type A syndrome of severe insulin resistance. J Clin Endocrinol Metab 1994;79:205-210.

32 Schoenle EJ, Zenobi PD, Torresani T, Werder EA, Zachmann M, Froesch ER: Recombinant human insulin-like growth factor I (rhIGF I) reduces hyperglycaemia in patients with extreme insulin resistance. Diabetologia 1991; 34:675-679.

33 Hochberg Z, Aviram M, Rubin D, Pollack S: Decreased sensitivity to insulin-like growth factor I in Turner's syndrome: a study of monocytes and $\mathrm{T}$ lymphocytes. Eur J Clin Invest 1997;27:543-547.

34 Janssen JA, Lamberts SW: Is the measurement of free IGF-I more indicative than that of total IGF- I in the evaluation of the biological activity of the GH/IGF-I axis? J Endocrinol Invest 1999;22:313-315.
35 Gravholt CH, Frystyk J, Flyvbjerg A, Orskov $\mathrm{H}$, Christiansen JS: Reduced free IGF-I and increased IGFBP-3 proteolysis in Turner syndrome: modulation by female sex steroids. Am J Physiol Endocrinol Metab 2001;280:E308E314.

36 Kannel WB, Dawber TR, Thomas HE Jr, McNamara PM: Comparison of serum lipids in the prediction of coronary heart disease. Framingham Study indicates that cholesterol level and blood pressure are major factors in coronary heart disease; effect of obesity and cigarette smoking also noted. R I Med J 1965;48: 243-250.

37 Thomas HE Jr, Kannel WB, Dawber TR, McNamara PM: Cholesterol-phospholipid ratio in the prediction of coronary heart disease. The Framingham Study. N Engl J Med 1966;274: 701-705.

38 Garden AS, Diver MJ, Fraser WD: Undiagnosed morbidity in adult women with Turner's syndrome. Clin Endocrinol (Oxf) 1996;45: 589-593.

>39 Ross JL, Feuillan P, Long LM, Kowal K, Kushner H, Cutler GB Jr: Lipid abnormalities in Turner syndrome. J Pediatr 1995; 126:242245.

40 Lanes R, Gunczler P, Palacios A, Villaroel O: Serum lipids, lipoprotein $\operatorname{lp}(\mathrm{a})$, and plasminogen activator inhibitor-1 in patients with Turner's syndrome before and during growth hormone and estrogen therapy. Fertil Steril 1997; 68:473-477.

41 Elsheikh M, Conway GS: The impact of obesity on cardiovascular risk factors in Turner's syndrome. Clin Endocrinol (Oxf) 1998;49: 447-450.

42 Cicognani A, Mazzanti L, Tassinari D, Pellacani A, Forabosco A, Landi L, Pifferi C, Cacciari E: Differences in carbohydrate tolerance in Turner syndrome depending on age and karyotype. Eur J Pediatr 1988;148:64-68.

43 Ehm M, Karnoub M, Sakul H, Gottschalk K, Holt D, Weber J: Genomewide search for type 2 diabetes susceptibility genes. Am J Hum Genet 2000;66:1871-1881.

44 Kadowaki T: Insights into insulin resistance and type 2 diabetes from knock out mouse models. J Clin Invest 2000;106:459-465.

45 Gloyn A, McCarthy M: The genetics of type 2 diabetes. Best Prac Res Clin Endocrinol Metab 2001;15:293-308. 